\title{
Research on the characteristics and emotional expression of musical literature
}

\author{
Yabing Wang ${ }^{1, a, *}$ \\ ${ }^{1}$ School of music and dance, Henan normal university, Xinxiang, 453007, P. R. China \\ aemail:xxwangyb@sina.com
}

Keywords: Musical literature, Emotional expression, Art space, Literary vision

\begin{abstract}
Musical literature belongs to a new research category which refer to the combination of music and literature. Either the perspective or the literary, the expression of music literature which is to fall in the emotional effect eventually, music literature is expressed through the emotion ultimately. The musical character and literary character are the two basic attributes of music literature. In this paper, music literature will be focused on the main characteristic and art form in terms of emotional expression.
\end{abstract}

\section{Introduction}

Musical literature is an art form which developed from music and literature. It majors in music and it is expressed by the form of literary work. Generally, musical literature is called lyrics. It just belongs to the cross position of music and literature[1]. The so called literary vision is displayed the literature through the language. It makes the human emotional expression more exquisite. On the art's level, literary vision enriches human's emotion. It has artistic features of the literary works. After the processing of literature and through more rich artistic channel, It makes common people accept and understand the art form of musical literature in a short time. It formed a unique music language expression[2]. In the abstract, Literature consciousness is an understanding and comprehension of literature. Thinking should be multidimensional for literature, not just understand literature itself. Musical literature is an art form which developed from music and literature. It not only has e artistic aesthetic feeling, but also has certain logic of art. It cannot reach cognitive level of music literature, just only for aesthetic perception of art and music[3]. The development of music literature is more traditional and the pattern of change is richer. Literature and music, under the cultural exchange has formed a new system. Music literature is a carrier of art and literature, but in contrast, it has a stronger and stronger aesthetic image.Virginia Woolf was one of the Modernist authors most interested in the potential musicality had for literature and her intermedial understanding of this concept is particularly revealing. Musical literature is an art form which developed from music and literature in form. It has the characteristics of both the music and literature. To a certain extent, the two formed the good complementary relationship. Music literature combined with the literature values and music influence. It is a form of potential performance. It guides the cognitive and values, cultivating people's aesthetic and feeling again.

\section{The characteristics of literature music}

Virginia Woolf was one of the Modernist authors most interested in the potential musicality had for literature and her intermedial understanding of this concept is particularly revealing. More than any other author of the period, she developed an aesthetics of literature in which musicality played a leading role. Virginia Woolf's lifelong interest in music and in the possible relations between music and literature is well documented and many of her novels underwent a process of musicalization. As she said in a letter in 1940 to Elizabeth Trevelyan,which is shown in figuer 1[4]. 


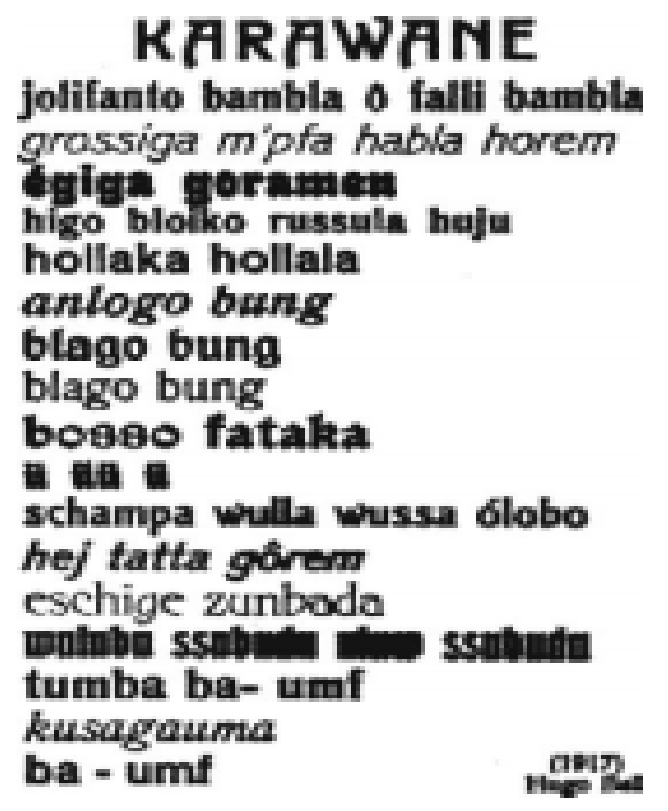

Fig. 1 Hugo Ball's ‘score’ for his sound poem 'Karawane’

To explore the value and function of music literature, we want to observe shanzhai culture on different cultural perspectives. There are a lot of information feedbacks on the literature view. It reflects the different audience' s psychological acceptance. The creativity of art space becomes stronger and stronger. Literature and music are not adapted to the individual form. The music under the literature view is paid more addition to the development of literature. The audience is not only master the meaning of literature, but also pursue the uniqueness of literature and expand the social function of literature. Based one the development of culture, It formed a specific cultural phenomenon. As shown in figure 1, Sofitel luxury hotels "music and literature" tour activities at sofitel wanda Beijing on May 8. The purpose of living is in the form of piano playing and reading interpretation of classical music and literature, for the audience to a French feelings with Chinese elements.

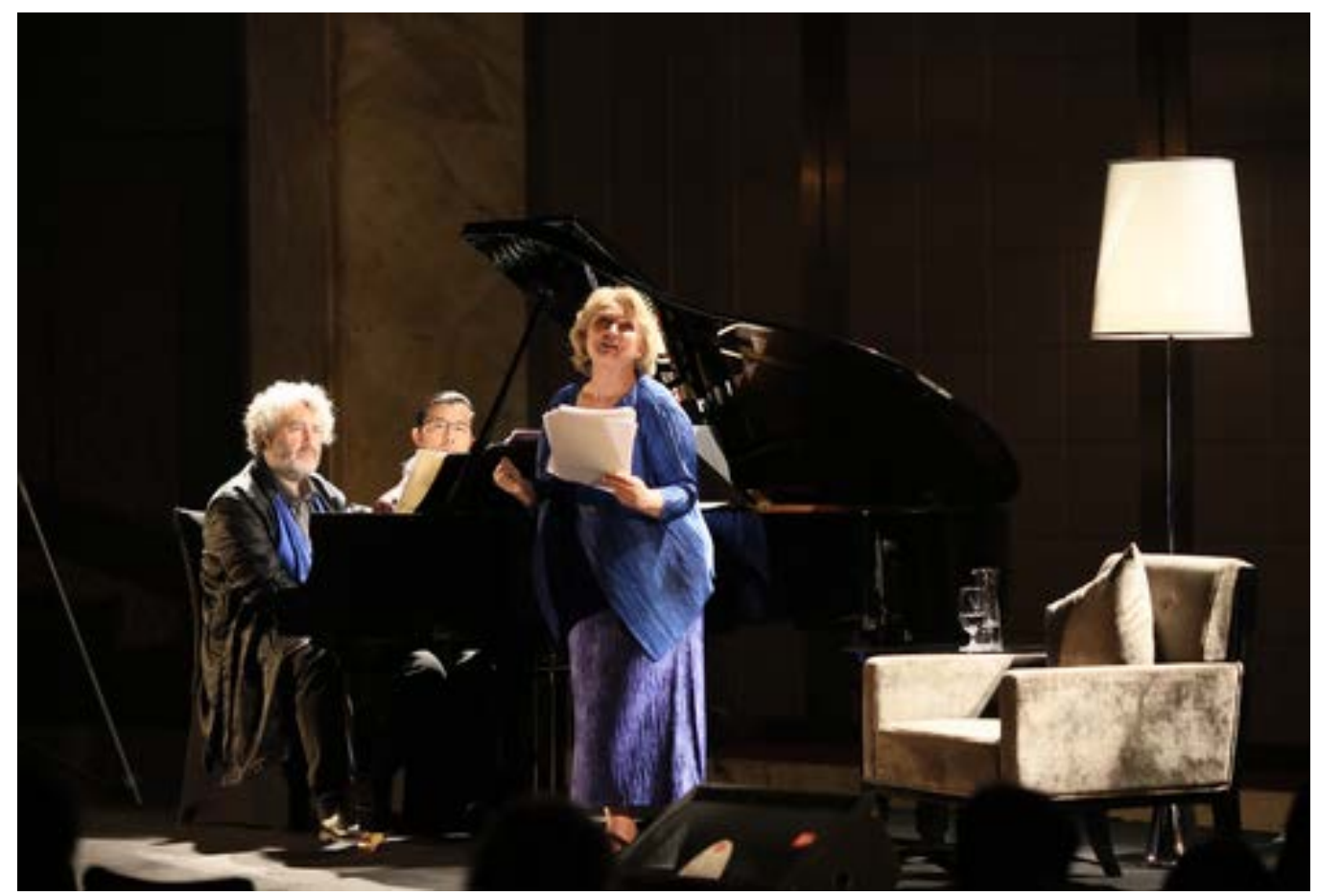

Fig.1 "Music and literature" tour photo 


\section{Music literature image}

Music literature image is very important for the expression of music culture. In the process of the development of music culture, Music literature image also acts as a very important role. The definition of music literature image has generality and aesthetic value of the picture.

Artistic image and life image has a certain corresponding relationship. The creation of music literature image also cannot leave the material life and life experience. Under the guidance of standard image, Music literature image should be united of music artistic image and literary and artistic image[5,6]. They must be unified in form.

In the process of music literature, it has many forms. Such as traditional drama and opera, modern musicals and score prose, etc. The common development of music and literature in a variety of forms are making progress and merging constantly. The fusion feature is reflected by the characteristics of music literature in society. Music literature is recreational, educational, artistic, and it shows the cultural function of literature, the revelation of music literature as shown in figure 2.

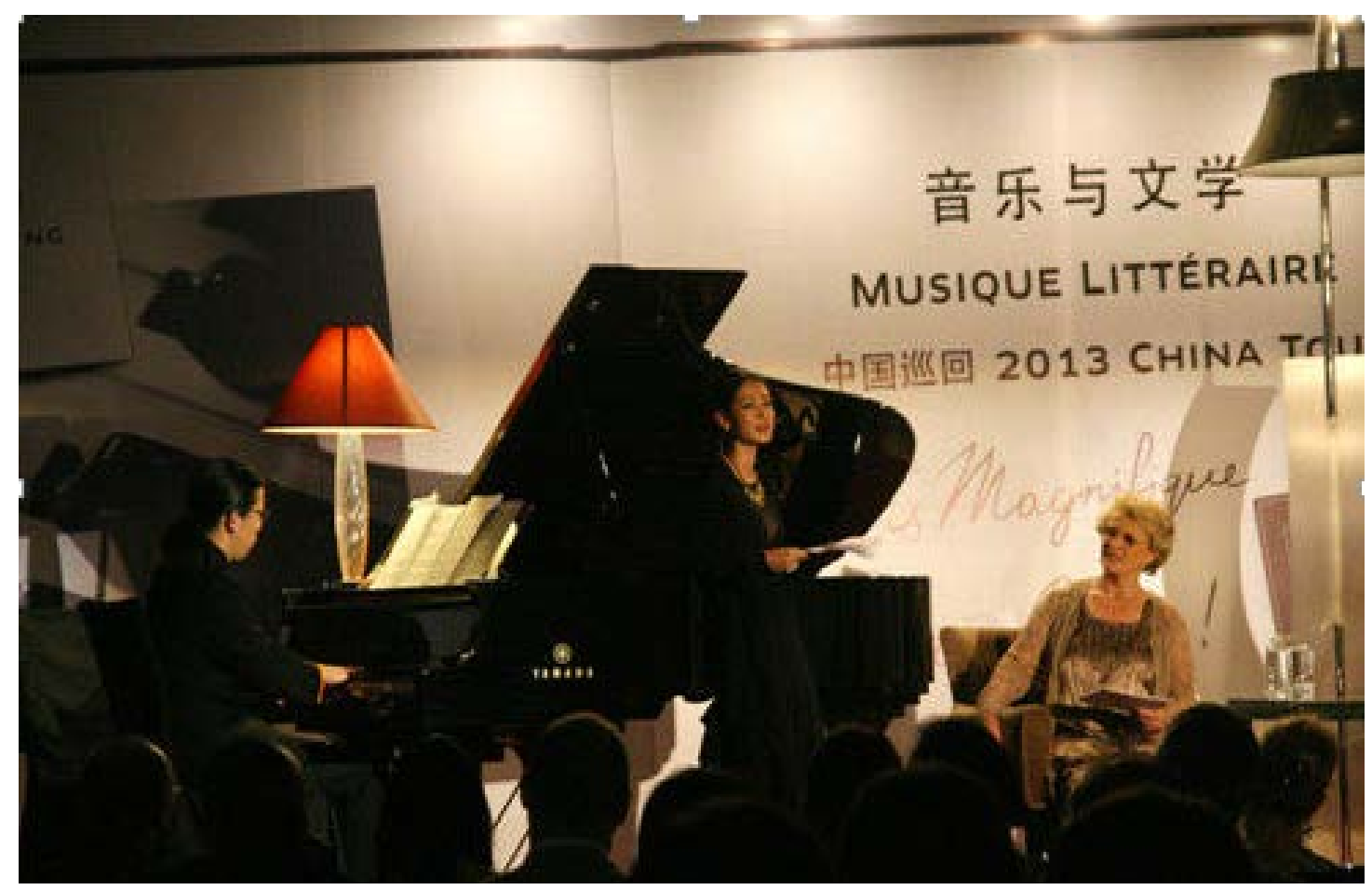

Fig.2 The revelation of music literature

\section{The formation of emotional music literature}

Music literature is a way for people to express their feelings. Music literature can reflect our specific feelings through the artistic image. The lyrics are the root of emotion, mainly because of the characteristics of music literature. In the process of the combination of music and literature, it accepts the characteristics of the two, and does not deny the specific characteristics of two kinds of art forms.

The lyrics is the emotional core of music literature and determine the emotional tone in the form of music literature. Once the emotional tone of music literature is made certain, the style of music is determined. The style of music is reflected by the lyrics as an important carrier of emotion.

The works of music literature and emotion have something in common, but also have something indifferent. Emotions are regarded as the reflection of the cognition of the world and guide the music emotion expression. According to the author's experience and artistic processing, Lyrics condensed the feelings in words. Through the music literature, it released its condensed emotion. There are some higher requirements for aesthetics and creation. 


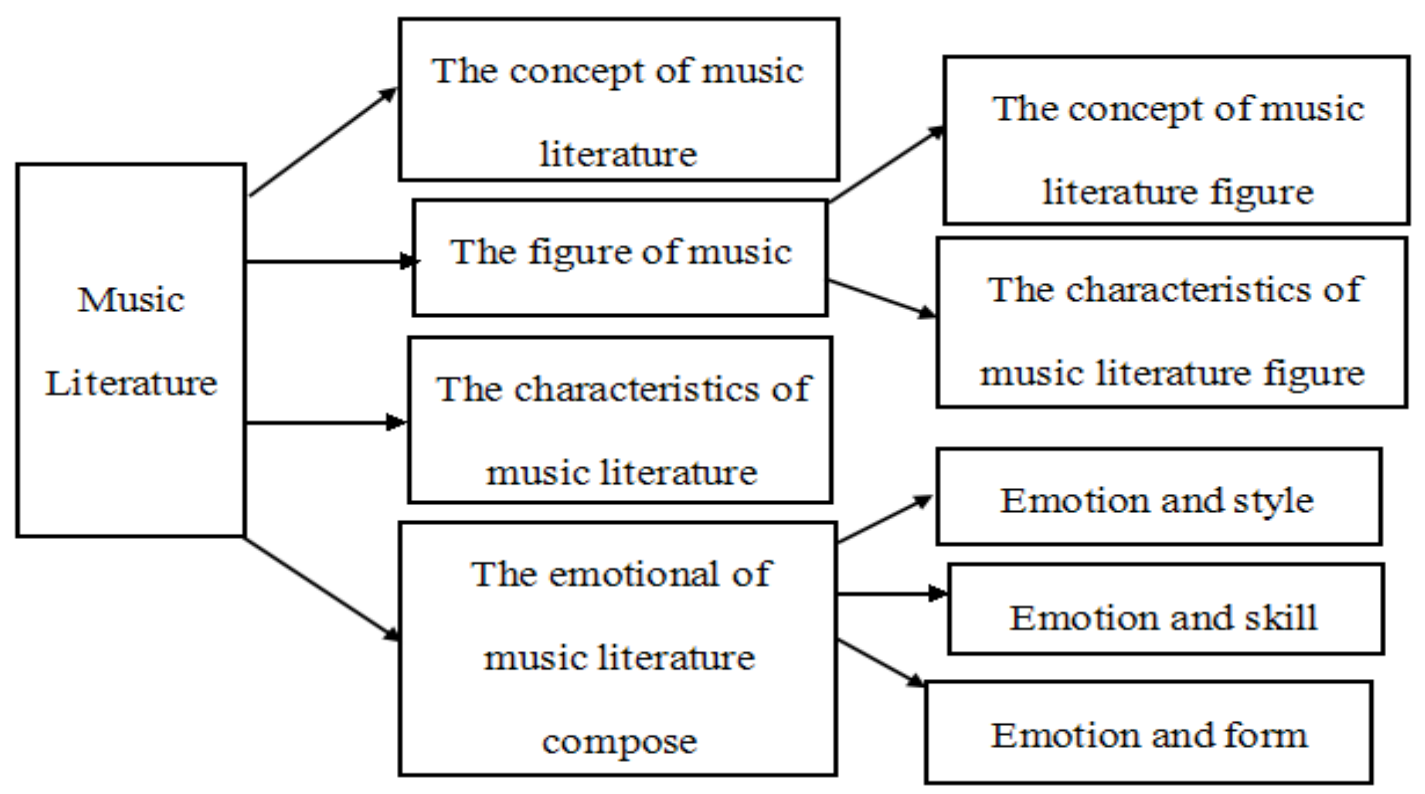

Fig.3 The content of music literature

The emotional expressions particular form of music literature is lyrics. Lyrics, through the different ways of expression, through the different image, through the different rhetorical devices, focus on art of tone and core ideas

Music literature expresses emotions through different images, such as expressing its emotion through natural scenery and expressing emotions through describing concrete objects. It expresses wants to convey thoughts though specific image and giving different understanding of the works. Music literature frame as shown in figure3.

The greatest involvement of significant others was cited in early memories for both literature and music.Non-majors were more likely to mention significant others in all categories, except early reading anecdotes. Table 1 shows a percent of subjects citing specific titles for literature and music by question and major[7].

Table 1. Percent Citations of Specific Music and Literature by Major

\begin{tabular}{|c|c|c|}
\hline & Music Majors & Nonmusic Majors \\
\hline Intense music & 42 & 63 \\
\hline Intense literature & 78 & 92 \\
\hline Early music & 49 & 73 \\
\hline Early literature & 75 & 71 \\
\hline
\end{tabular}

\section{Conclusions}

In short, music literature is full of human feelings and full of rich expression forms of the art world. As the root of the art world, Emotions make people accept the works of music literature and get more profound understanding. The expression of emotion for music literature is consistent with the emotional needs of the people. Music literature is an art of interaction with people's inner feelings. So emotions play a very important role in music literature. 


\section{References}

[1] D. Santanu, Touch and Intimacy in First World War Literature. Cambridge: Cambridge University Press, 2005.

[2] S. Charles, M. Mather and L. Carstensen, Aging and emotionalmemory: The forgettable nature of negative images for older adults, Journal of Experimental Psychology, Vol. 132, (2003)310-324.

[3] R. Suzanne and T. T. eds, Women' s Fiction and the Great War. Oxford: Clarendon Press, 1997.

[4] A. Gabrielsson, Old people's remembrance of strong experiences related to music, Psychomusicology, vol. 18, (2002)103-122.

[5] C. K. Madsen and R. A. Duke, First remembrances of music.General Music Today, vol. 13, (1999)19-22.

[6] T. Kendall, Modern English War Poetry. Oxford: Oxford University Press, 2006.

[7] L. Zuo, Creativity and aesthetic sense, Creativity Research Journal, vol. 11, (1998)309-313. 